\title{
Genistein Inhibits Human Colorectal Cancer Growth and Suppresses MiR-95, Akt and SGK1
}

\author{
Jian Qin ${ }^{\mathrm{a}} \quad$ Jia Xin Chen ${ }^{\mathrm{a}}$ Zhou Zhu ${ }^{\mathrm{b}} \quad$ Jia An Teng ${ }^{\mathrm{c}}$ \\ aDepartment of Radiation Oncology of Clinical Cancer Center, the People's Hospital of Guangxi Zhuang \\ Autonomous Region, Nanning, 'Department of Gastrointestinal and Peripheral Vascular Surgery, the \\ People's Hospital of Guangxi Zhuang Autonomous Region, Nanning, 'Department of Cadre Medicine, \\ Division of Endocrinology and metabolism, People's Hospital of Guang xi Zhuang Autonomous Region, \\ Nanning, China
}

\author{
Key Words \\ Genistein • Apoptosis • Colorectal cancer cell • Akt • Bax
}

\begin{abstract}
Background: Genistein, a major isoflavonoid isolated from dietary soybean, has been shown to suppress the growth of several cancers through modulation of various pathways. However, the molecular mechanisms by which genistein elicit its effects on colorectal cancer (CRC) cells have not been fully elucidated. In this study, we aimed to investigate the anti-tumor activities of genistein on CRC and its potential mechanism. Methods: Effects of genistein on the cell proliferation were tested in HCT-116 cells by MTT assay, and apoptosis was measured by Flow cytometry. Real-time PCR was also used to evaluate the regulation of genistein on miR-95, Akt and SGK1 expression. The protein levels of total Akt (T-Akt), and phosphorylated Akt (P-Akt) were assessed by western blot. A nude mice xenograft model was employed to determine whether genistein could have an anti-tumor effect on CRC in vivo. Results: We found that treatment of HCT-116 cells with genistein caused an inhibition of cell proliferation and induction of apoptosis. Meanwhile, genistein down-regulated the mRNA expression of Akt, SGK1 and miR-95, and inhibited the phosphorylation of Akt in HCT-116 cells. The experiment in vivo also showed that genistein significantly suppressed the growth of mouse xenograft tumor. Conclusion: This study demonstrates that genistein has an inhibitory effect on CRC involved in reducing miR-95, Akt and SGK1, offering novel insights into the mechanisms of genistein therapeutic actions.
\end{abstract}

Jia An Teng,

KARGER 125
Department of Cadre Medicine, Division of Endocrinology and metabolism, People's Hospital of Guang xi Zhuang Autonomous Region, Nanning, 530021 (China) Tel. +86-7712186503, E-Mail qinjian12345@yeah.net 


\section{Cellular Physiology Cell Physiol Biochem 2015;35:2069-2077 \begin{tabular}{l|l} 
and Biochemistry Published onIIne: AprIII, 2015 & $\begin{array}{l}\text { C 2015 S. Karger AG, Basel } \\
\text { www.karger.com/cpb }\end{array}$ \\
\hline
\end{tabular} Qin et al.: Genistein Inhibits Colorectal Cancer Growth}

\section{Introduction}

Colorectal cancer (CRC) is one of the most common malignancies and a leading cause of cancer deaths worldwide. Increased incidence of CRC has also been observed in recent years, likely due to associated changes in diet and environment. Despite achievements in the treatment in the few past decades, CRC remains a major public health concern. The enhanced drug resistance and the side effects resulting from the application of traditional radiotherapy and chemotherapy is therefore a major problem in the treatment of CRC [1-3]. Thus, there is an urgent need to explore effective anti-tumor drug candidates with fewer side effects for the treatment of CRC. Interestingly, epidemiologic studies have showed that Asians have a lower incidence of gastrointestinal cancer including CRC, presumably due to higher amounts of phytoestrogen-rich soy diet in Asians [4, 5]. These findings demonstrate that the phytoestrogen constituents of soy possess anticarcinogenic properties and reduce the incidence of colorectal neoplasias.

Genistein (49,5,7-Trihydroxyisoflavone), a major phytoestrogen constituent of soybeans and soy products, has been shown to exhibit inhibition effects on a variety of malignancies such as CRC [6], prostate cancer [7], breast cancer [8], and lung cancer [9]. Genistein is a protein tyrosine kinase inhibitor and affects cell proliferation, apoptosis, tumor angiogenesis, metastasis and attenuates multidrug resistance through the regulation of key components of signal transduction pathways such as Akt [8], SGK1 [10], EGFR [11], and MAPK [12]. Akt, also known as protein kinase $\mathrm{B}(\mathrm{PKB})$, is a serine/threonine kinase and a major downstream effector of phosphatidylinositide-3-kinase (PI3K). Aberrant activation of Akt is associated with the development and progression of many human cancers, including CRC [13]. Previous study has shown that genistein inhibits human colon cancer cell Caco2 migration, accompanied with decrease of Akt phosphorylation, suggesting that suppression of the Akt signaling pathway may involved in the anti-tumor effects of genistein in CRC [14]. In addition, other tumor-related factors, such as FLT4 [6], estrogen receptor (ER) $\beta$ [15], and EGFR [16] have also been demostreated to participate in the anti-proliferation and apoptosis-induced effects of genistein on CRC. However, the roles and potential mechanisms of genistein in CRC are still largely unknown.

Moreover, recent analysises suggest that genistein suppresses the growth of several cancer cell lines in vitro and in vivo by reducing the expression of several oncogenic microRNAs (miRNAs) [7, 17-20]. miRNAs are endogenous, non-coding small RNAs, approximately 1825 nucleotide molecules that negatively regulate the expression of a wide variety of genes by complementary binding to the mRNA 3'-untranslated regions (3' UTR) in a sequence-specific manner, resulting in cleavage or translational repression of the target mRNA. Increasing evidence shows that miRNAs play an important part in many biological processes, such as development, differentiation, proliferation, apoptosis, angiogenesis and metabolism. They are key regulators in many diseases including cancer $[21,22]$. miR-95 was reported to be frequently up-regulated in CRC and might act as an important oncogene in tumor glowth, invasion, and metastasis [23]. The effects of genistein on the regulation of several miRNAs have been reported. However, the effects of genistein on miR-95 have not been known.

Therefore in this study we investigate the anti-tumor effects of genistein on CRC in vitro and in vivo, and to explore the underlying mechanisms involved in the biological actions of genistein.

\section{Materials and Methods}

\section{Cell culture and genistein treatment}

The human CRC cell line HCT-116 was obtained from Shanghai Institute of Cell Biology (the Chinese Academy of Sciences, Shanghai, China). Cells were cultured in RPMI-1640 (Gibco, USA) supplemented with $10 \%$ fetal bovine serum (Hyclone Co. Ltd, USA), $100 \mathrm{U} / \mathrm{mL}$ penicillin, $100 \mu \mathrm{g} / \mathrm{mL}$ streptomycin, and kept at $37^{\circ} \mathrm{C}$ in a humidified $5 \% \mathrm{CO}_{2}$ incubator. The cells $(60 \%-70 \%$ confluent) were treated with genistein (Sigma, 


\section{Cellular Physiology Cell Physiol Biochem 2015;35:2069-2077

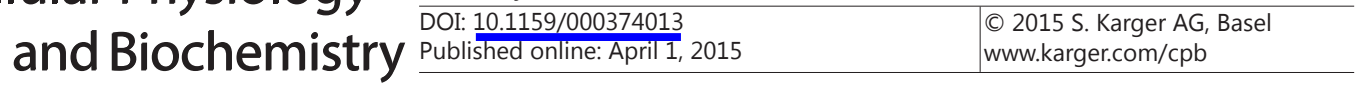 \\ Qin et al.: Genistein Inhibits Colorectal Cancer Growth}

USA) dissolved in dimethylsulfoxide (DMSO) and cells treated with vehicle (DMSO) served as control. All cells were starved with low-serum medium (contain $0.5 \%$ CS-FBS) for $24 \mathrm{~h}$ before the experiments.

\section{Cell proliferation assay}

Effect of genistein on proliferation was assessed with 3-(4,5-dimethylthiazol-2-yl)-2,5-diphenyl tetrazolium bromide (MTT) assay. In brief, HCT- 116 cells were plated at a density of $4 \times 10^{3}$ cells/well into 96-well plates. After $24 \mathrm{~h}$ incubation, cells were treated with genistein at different final concentrations $(0$, $5,10,20,40,60,80,100 \mu \mathrm{M})$ for $48 \mathrm{~h}$. At the end of treatment, $20 \mu \mathrm{lTT}(5 \mathrm{mg} / \mathrm{ml})$ was added to each well and incubated for additional $4 \mathrm{~h}$. Then the medium was removed, and $150 \mu \mathrm{l}$ DMSO was added to each well to dissolve the sediment. The optical density (OD) for each well was measured using a microplate reader (Bio-Rad, USA) after shaken for $10 \mathrm{~min}$ at a wavelength of $570 \mathrm{~nm}$. The $50 \%$ inhibitory concentration $\left(\mathrm{IC}_{50}\right.$ ) of the $48 \mathrm{~h}$ was calculated with the Bliss method.

Flow Cytometry

The cell apoptosis was evaluated by flow cytometry analysis. After being incubated with various concentrations of genistein $(25,50,100 \mu \mathrm{M})$ for $48 \mathrm{~h}$, cells were harvested and dual stained with Annexin V-FITC and propidium iodide (PI) using an Apoptosis Detection Kit (Kaiji, China) following the the manufacturer's protocol. Stained cells were immediately analysed by the flow cytometry (Becton Dickinson, USA). Viable cells are primarily Annexin V-FITC and PI negative, PI positive staining indicates necrosis, and only cells that stained with annexinV were considered to undergo early-stage apoptosis.

RNA isolation and real-time PCR

Total RNA was isolated from cultured cells after stimulation with genistein for $48 \mathrm{~h}$ using Trizol reagent (Invitrogen, USA) according to manufacturer's instructions. Then, cDNA synthesis was performed using the RevertAid $^{\mathrm{TM}}$ First Strand cDNA Synthesis Kit (Fermentas, USA). For detection of miR-95 expression, stemloop RT-PCR was performed. Then, the expressions of miR-95, Akt, and SGK1 were measured by real-time PCR using SYBR Premix Ex Taq ${ }^{\text {TM }}$ (Takara, Japan) according to the manufacturer's protocol. U6 small nuclear RNA (U6) and Glyceraldehyde-3-phosphate dehydrogenase (GAPDH) gene were served as the internal reference. The relative expression was calculated using the $2^{-\Delta c t}$ method.

\section{Western blot analysis}

After treated with different concentrations of genistein for $48 \mathrm{~h}$, the cells were harvested with ice-cold PBS and lysed on ice in lysis buffer for $30 \mathrm{~min}$. The lysates were centrifuged 12,000 rpm for $10 \mathrm{~min}$, and the resulting supernatants were determined by Bio-Rad assay kit using bovine serum albumin as the standard. Equal amounts of proteins were electrophosed by SDS-PAGE gels and subsequently transferred to PVDF membranes (Bio-Rad laboratories, USA). Membranes were blocked with $5 \%$ nonfat dried milk in TBST

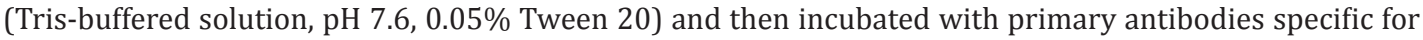
T-Akt (1:1000), p-Akt (1:1000 dilution, Santa Cruz Biotechnology, Germany), at room temperature for $2 \mathrm{~h}$. After three washes, the blots were subsequently incubated with appropriate secondary antibodies $(1: 2000)$ coupled to horseradish peroxidase at room temperature for $1 \mathrm{~h}$, and developed in the ECL Western detection reagents (Beyotime, China). Band density was quantified using the software program Bio-Rad Quantity One v4.62.

\section{In vivo anti-tumor activity}

Forty 4-5 week-old female nude mice were purchased from the Experimental Animal Center of Guangxi Medical University. Then the mice were inoculated with HCT-116 cell suspension $\left(1 \times 10^{7} / \mathrm{mL}\right), 0.2 \mathrm{~mL}$ per mouse, through subcutaneous injection to the right side axilla.

Ten days after the tumor cell inoculation, the mice were randomly divided in to four groups of ten mice. Mice in three genistein groups were given 20, $50,80 \mathrm{mg} / \mathrm{kg}$ genistein dissolved in $0.1 \%$ DMSO solution through intraperitoneal injection, and the vehicle control group was injected with an equal volume of $0.1 \%$ DMSO solution daily for 2 weeks. The tumor volume (V) was measured every other day, and calculated according to the formula: $\mathrm{V}\left(\mathrm{mm}^{3}\right)=\mathrm{ab}^{2} / 2$. Where $\mathrm{a}$ is the largest superficial diameter and $\mathrm{b}$ is the smallest superficial diameter.

\section{KARGER}


All mice were sacrificed 24 days after inoculation, and the transplanted tumors were exercised and weighed. The animal handling and experimental procedures were approved by the Animal Care and Use Committee of Guangxi Medical University.

Statistical analysis

Data were analyzed using analysis of variance (ANOVA) as appropriate. All statistics and data analysis were performed using SPSS 13.0 software (SPSS Inc., USA). Data were presented as means \pm standard deviation (SD) $\mathrm{P}<0.05$ was considered statistically significant.

\section{Results}

Genistein inhibits proliferation of HCT-116 cells

In order to evaluate the anti-proliferative effects of genistein in the HCT-116 cells, the cells were treated with increasing concentrations of genistein for 48 hours, and the cell viability was determined by MTT assay. Results show that genistein dose-dependently significantly inhibited the proliferation of HCT-116 cells (Fig. 1). And the IC $_{50}$ value for genistein at $48 \mathrm{~h}$ was $39.43 \mu \mathrm{M}$.

\section{Genistein induces apoptosis in HCT-116 cells}

After $48 \mathrm{~h}$ incubation of HCT-116 cells with different concentrations of genistein, flow cytometric analysis was performed to determine whether genistein can induce apoptosis in CRC cells. As shown in Fig. 2, the cells in negative control group showed 10.03\% apoptosis rate. However, after treatment with genistein $(25,50$, and $100 \mu \mathrm{M})$ for $48 \mathrm{~h}$, the apoptosis percentage increased to $18.47 \%(\mathrm{p}<0.05), 34.97 \%(\mathrm{p}<0.01)$, and $63.2 \%(\mathrm{p}<0.01)$. These data indicated that genistein could induce apoptosis of HCT-116 cells in a dose-dependent manner.

Genistein regulates the expression of miR-95, Akt and SGK1 mRNA

To explore which molecular mechanisms are involved in the ati-tumor effects of genistein on CRC, the expressions of miR-95, Akt and SGK1 mRNA were detected by real time-PCR. As shown in Figure 3, the levels of miR-95, Akt and SGK1 mRNA expression were significantly down-regulated after incubation with genistein for $48 \mathrm{~h}$, especially in the 50 and $100 \mu \mathrm{M}(\mathrm{p}<0.01)$ genistein-treated group as compared with untreated cells.

Genistein decreases the phosphorylation of Akt

To assess whether genistein inhibits cell proliferation and induces cell apoptosis through PI3K/Akt pathway, we determined the phosphorylation of Akt in genistein-treated HCT-116 cells by western blot analysis. Compared with the untreated control, genistein significantly decreased the phosphorylation of Akt (Fig. 4).

Fig. 1. Anti-proliferative effect of genistein on CRC cell HCT-116. Cells were treated with various concentrations of genistein for $48 \mathrm{~h}$, and then analyzed for viability by MTT. Data were shown as mean \pm SD of three independent experiments.

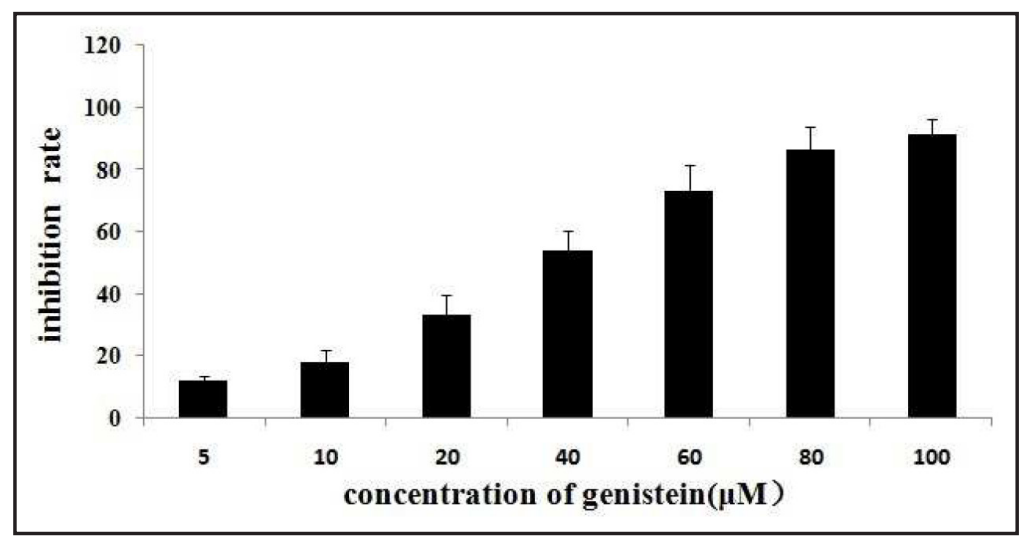


Fig. 2. Effect of genistein on apoptosis of HCT-116 cells. Apoptosis of HCT-116 cells after treatment with 0,25 , 50 , and $100 \mu \mathrm{M}$ genistein was examined by flow cytometry. Representative scatter grams from flow cytometry profile represent Annexin V-FITC (AV) staining on the $\mathrm{x}$ axis and PI on the $y$ axis. Percentages of apoptotic cells are shown in the histogram. Data were shown as mean \pm SD of three independent experiments. ${ }^{*} \mathrm{p}<0.05,{ }^{* *} \mathrm{p}<0.01$ vs negative control.

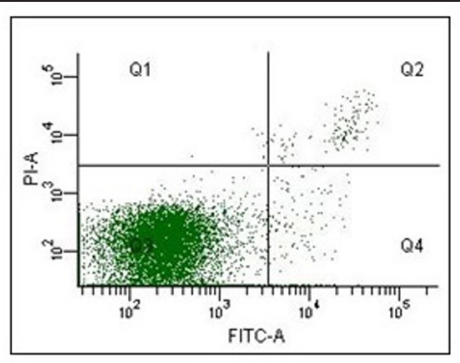

$\mathbf{0} \boldsymbol{\mu M}$

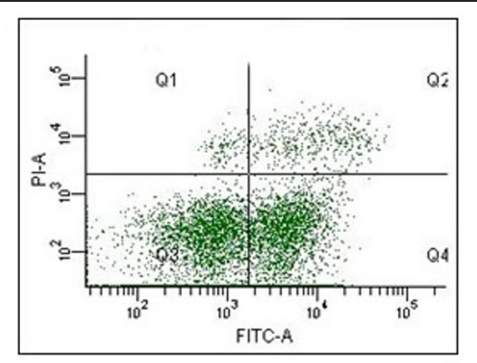

$100 \mu \mathrm{M}$

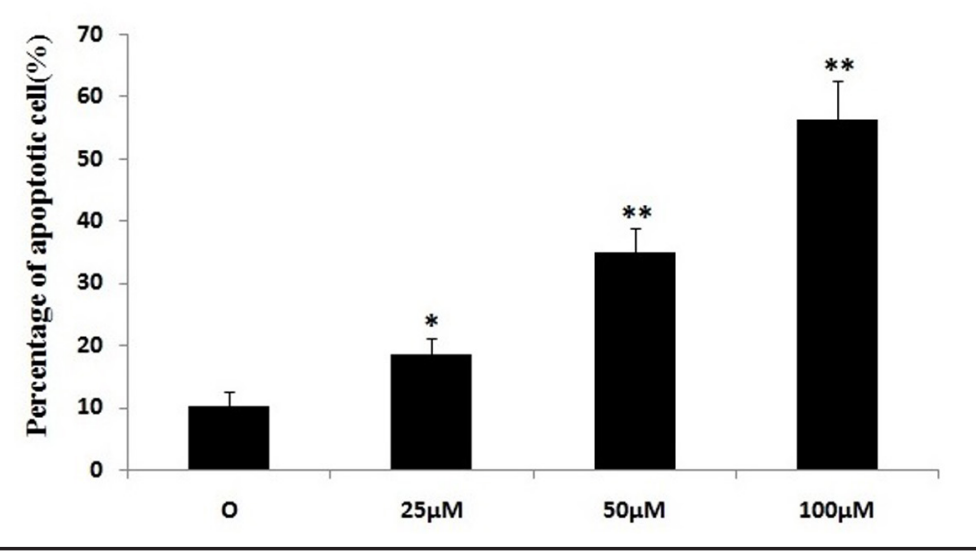

Fig. 3. Effect of genistein on miR-95, Akt and SGK1 mRNA expression in HCT-116 cells. Cells were incubated with increasing concentrations of genistein $(25-100 \mu \mathrm{M})$ for 48 h. The gene expression was detected by real-time PCR reaction array. The results were normalized to U6 or GAPDH expression and ex-

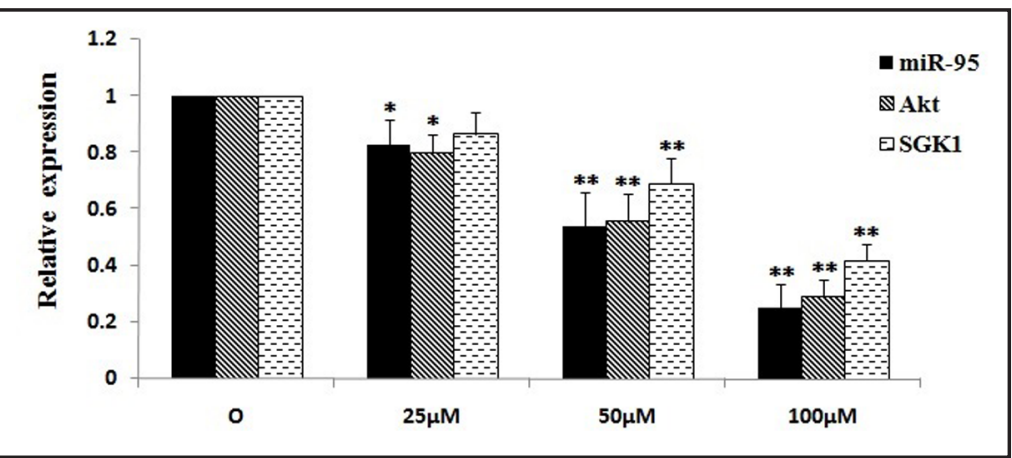

pressed as fold change relative to the negative control (untreated cells). Data were shown as mean \pm SD of three independent experiments. ${ }^{*} \mathrm{p}<0.05,{ }^{* *} \mathrm{p}<0.01$ vs negative control.

\section{Genistein suppresses the growth of CRC in vivo}

To determine whether genistein could have an anti-tumor effect on CRC in vivo, we utilized a xenograft model of HCT-116 cells in nude mice. The growth curve of transplanted tumor showed that genistein significantly suppressed tumor growth in a dose- and timedependent manner (Fig. 5A). And the average tumor weights in genistein-treated mice were $77.56 \%, 57.82 \%$ and $41.50 \%$ of that in control animals $(\mathrm{P}<0.05)$ (Fig. 5B). The results showed that genistein remarkably suppressed the transplanted CRC tumor volume and weight in vivo.

\section{Discussion and Conclusion}

Genistein, the main component of isoflavones, have been shown to regulate cancer cell proliferation, invasion, angiogenesis and metastasis by targeting several genes and signaling 
Fig. 4. Effect of genistein on the phosphorylation of Akt in HCT-116 cells. HCT-116 cells were treated with 0,25 , 50 , and $100 \mu \mathrm{M}$ of genistein for $48 \mathrm{~h}$. Total protein was extracted for immune-blotting of p-Akt and T-Akt. Data were shown as mean \pm SD of three independent experiments. ${ }^{* *} \mathrm{p}<0.01$ vs negative control.

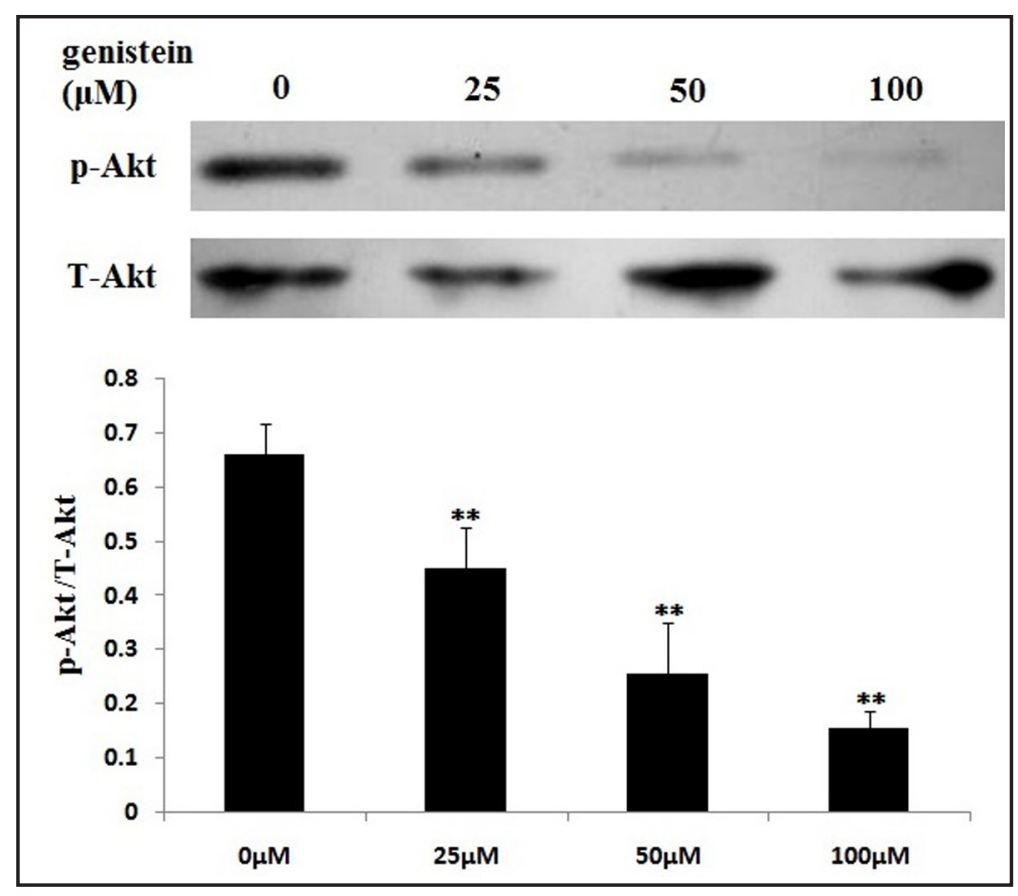

Fig. 5. Anti-tumor effects of genistein in vivo. HCT-116 cells were inoculated subcutaneously into the nude mice for 10 days, and then were treated daily with 20 , $40,80 \mathrm{mg} / \mathrm{kg}$ genistein. After 2 weeks of treatment, mice were sacrificed. (A) The growth curve of mouse xenograft tumor; (B) The weight of xenograft tumor. Data were shown as mean \pm SD of three independent experiments, $\mathrm{n}=10$.

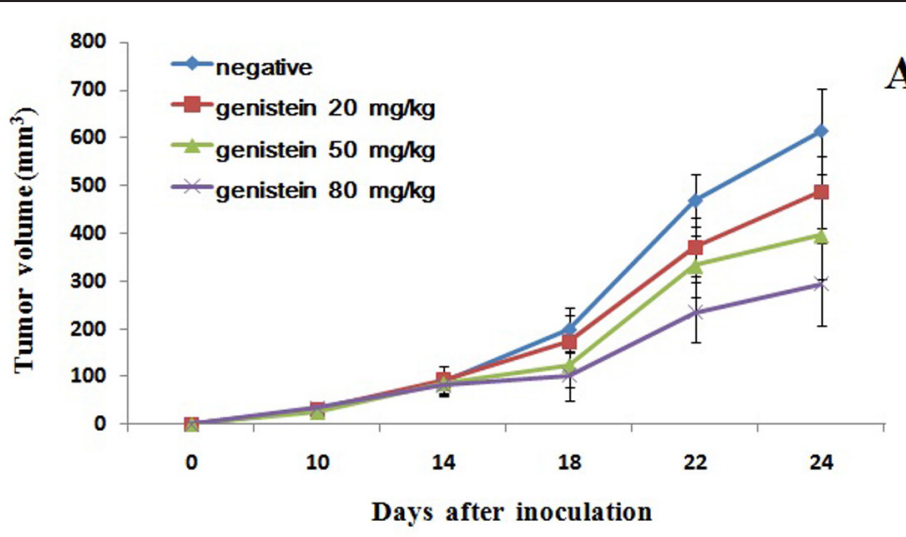

A

B

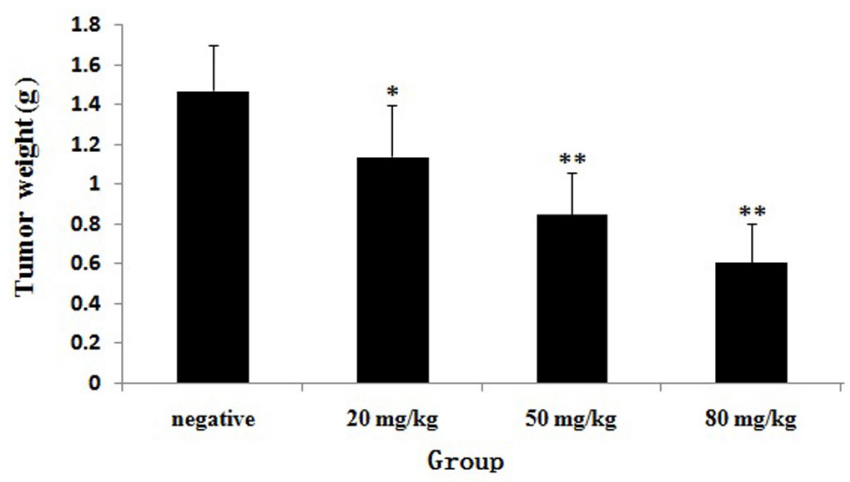

pathways. Such as, Tian et al. found that genistein exerted multiple anti-tumor effects to suppress proliferation, induce cell cycle arrest, and trigger apoptosis in H446 small-cell lung cancer (SCLC) cell line at least partly mediated by the down-regulation of FoxM1 [9]. Genistein has also been reported to inhibit invasion and metastasis of human cervical cancer cells HeLa by modulation of MMP-9 and TIMP-1 [24]. Similarly, in CRC, genistein also exhibited 
a potentially cancer-protective ability in the tumor development and progression. Xiao at al found that genistein could inhibit human CRC cell proliferation invasion and migration at non-cytotoxic concentrations by reducing FLT4. And oral genistein could also inhibit distant metastasis formation and suppressed neo-angiogenesis in transplanted tumors [6]. In addition, it has been reported that the anti-tumor effects of genistein on CRC also involved with suppression WNT, NF- $\kappa$ B cell Signaling pathway, and modulation of apoptotic gene Bcl-2, Box, EGFR, and ROS [16, 25-27]. Those findings suggested that genistein possesses effectively anti-cancer effects on CRC without any visible toxicity through the regulation of several signaling pathways. In the present study, we detected the biological effects of genistein in CRC. Consistent with previous results, genistein markedly inhibited cell proliferation and induced apoptosis of HCT-116 cells in a dose-dependent manner. Furthermore, we also found that genistein dramatically suppressed the growth of mouse xenograft tumor in vivo.

Activation of the PI3K/Akt pathway has been widely reported to promote cell survival by inhibiting apoptosis. Akt, a major component of the PI3K/Akt pathway, acts as a signal transducer of PI3K. Akt activation depends on its phosphorylation at T308 within its catalytic domain by phosphoinositol-dependent kinase 1 (PDK1) and at S473. Subsequently, its activation stimulates apoptosis, cell cycle progression, survival and metabolism through the phosphorylation of many substrates, such as GSK3, BAX, and mTOR [13]. Moreover, the SGK1 is a recently identified member of the AGC family of serine/threonine kinases, which shares $50 \%$ similarity in its aminoacid sequence with other members of the family such as Akt/PKB, PKA and PKC-zeta. It has been found that SGK1 could be regulated by a variety of signaling pathways including PKC, MAPK, and calcium, and enhances survival, invasiveness, motility, epithelial to mesenchymal transition (EMT) and adhesiveness of tumour cells through several kinases and transcription factors [28]. In the latest study, Chen et al. demonstrated that genistein inhibited breast cancer cell growth through inactivation of the PI3K/Akt signaling pathway [8]. Similarly, SGK1 induction was also found to be sensitive to the tyrosine kinase inhibitor genistein [10]. Meanwhile, the activation of PI3K/Akt pathway and SGK1 has been indicated to be significantly associated with CRC development and progression $[13,29]$. It suggested that modulation of Akt and SGK1 expression may be involved in the anti-tumor effects of genistein on CRC. Therefore, we analyzed the mRNA expression of Akt and SGK1, and phosphorylation of Akt in genistein-treated HCT-116 cells. As expected, the results showed that genistein down-regulated Akt and SGK1 mRNA expression, and inhibited phosphorylation of Akt.

miRNAs, which were aberrant expression in numerous malignant tumors, have been recognized as tumor suppressors or oncogenes, and regulate numerous important cancerrelated genes $[21,22]$. In CRC, miR-95 has been shown to be frequently up-regulated in tumor tissues, and function as an oncogene involved in cell proliferation and apoptosis ${ }^{[23]}$. According to recent reports, miRNAs might also participate in the pleiotropic biological effects of genistein. Such as, Xu at al found that expression of miR-27a was higher in human ovarian cancer, while genistein could block ovarian cancer cell growth and migration by suppressing oncogenic miR-27a [18]. Zaman at al. observed that genistein inhibited the expression of miR-21 in kidney cancer cells A-498 and in the tumors formed after injecting genistein treated A-498 cells in nude mice along with inhibiting tumor formation [19]. Similarly, Chiyomaru at al also demonstrated that genistein suppressed prostate cancer cell proliferation, migration and invasion through inhibition of oncogenic miR-151 [7]. The tumor suppressor microRNA-574-3p in prostate cancer has shown to be up-regulated by genistein [20]. However, the effect of genistein on the regulation of oncogenic miR-95 has not been reported. In this study, we showed that genistein treatment significantly downregulated the relative expression level of miR-95. This is the first report to investigate the influence of genistein on miR-95 expression.

In conclusion, our results show that genistein has a significant inhibitory effect on CRC both in vitro and in vivo. Moreover, the current study suggested that down-regulation of oncogenic miR-95, Akt and SGK1, and inhibition of phosphorylation of Akt might be associated with the anti-tumor effects of genistein in CRC. Therefore, these findings help us 
further understand the protective ability and potential mechanisms of genistein in CRC and provide the valuable references for the clinical use of genistein as a dietary therapeutic agent for CRC. Further investigation of the genistein as an anti-tumor compound is warranted.

\section{Disclosure Statement}

The authors report that they have no conflicts of interest. The authors alone are responsible for the content and writing of this article. This study is supported by the National Natural Science Foundation of China (No. 81160107), Guangxi Science Research and Technique Development Plan Foundation (No. 1104003B-69), and Guangxi Natural Science Foundation (No. 2010GXNSFB013083).

\section{References}

- Siegel R, Ma J, Zou Z, Jemal A: Cancer statistics, 2014. CA Cancer J Clin 2014;64:9-29.

-2 Wei EK, Colditz GA, Giovannucci EL, Fuchs CS, Rosner BA: Cumulative risk of colon cancer up to age 70 years by risk factor status using data from the Nurses' Health Study. Am J Epidemiol 2009;170:863-872.

-3 Cutsem EV, Nordlinger B, Cervantes A: Advanced colorectal cancer: ESMO clinical practice guidelines for treatment. Annals of Oncology 2010;21:93-97.

- 4 Birt DF, Hendrich S, Wang W: Dietary agents in cancer prevention: flavonoids and isoflavonoids. Pharmacol Ther 2001;90:157-177.

-5 Ko KP, Park SK, Park B, Yang JJ, Cho LY, Kang C, Kim CS, Gwack J, Shin A, Kim Y, Kim J, Yang HK, Kang D, Chang SH, Shin HR, Yoo KY: Isoflavones from phytoestrogens and gastric cancer risk: a nested case-control study within the Korean Multicenter Cancer Cohort. Cancer Epidemiol Biomarkers Prev 2010;19:12921300 .

6 Pampaloni B, Palmini G, Mavilia C, Zonefrati R, Tanini A, Brandi ML: In vitro effects of polyphenols on colorectal cancer cells. World J Gastrointest Oncol 2014;6:289-300.

-7 Chiyomaru T, Yamamura S, Zaman MS, Majid S, Deng G, Shahryari V, Saini S, Hirata H, Ueno K, Chang I, Tanaka Y, Tabatabai ZL, Enokida H, Nakagawa M, Dahiya R: Genistein suppresses prostate cancer growth through inhibition of oncogenic microRNA-151. PLoS One DOI: 10.1371/journal.pone.0043812.

8 Chen J, Lin C, Yong W, Ye Y, Huang Z: Calycosin and Genistein Induce Apoptosis by Inactivation of HOTAIR/ p-Akt Signaling Pathway in Human Breast Cancer MCF-7 Cells. Cell Physiol Biochem 2015;35:722-728.

9 Tian T, Li J, Li B, Wang Y, Li M, Ma D, Wang X: Genistein exhibits anti-cancer effects via down-regulating FoxM1 in H446 small-cell lung cancer cells. Tumour Biol 2014;35:4137-4145.

10 Baskin R, Sayeski PP: Angiotensin II mediates cell survival through upregulation and activation of the serum and glucocorticoid inducible kinase 1. Cell Signal 2012;24:435-442.

-11 Yan GR, Xiao CL, He GW, Yin XF, Chen NP, Cao Y, He QY: Global phosphoproteomic effects of natural tyrosine kinase inhibitor, genistein, on signaling pathways. Proteomics 2010;10:976-986.

12 Chen J, Hou R, Zhang X, Ye Y, Wang Y, Tian J: Calycosin Suppresses Breast Cancer Cell Growth via ERbDependent Regulation of IGF-1R, p38 MAPK and PI3K/Akt Pathways. PLoS One DOI: 10.1371/journal. pone.0091245.

13 Danielsen SA, Eide PW, Nesbakken A, Guren T, Leithe E, Lothe RA: Portrait of the PI3K/AKT pathway in colorectal cancer. Biochim Biophys Acta 2015;1855:104-121.

14 Gu S, Papadopoulou N, Nasir O, Föller M, Alevizopoulos K, Lang F, Stournaras C: Activation of membrane androgen receptors in colon cancer inhibits the prosurvival signals Akt/badin vitro and in vivo and blocks migration via vinculin/actin signaling. Mol Med 2011;17:48-58.

15 Pampaloni B, Palmini G, Mavilia C, Zonefrati R, Tanini A, Brandi ML: In vitro effects of polyphenols on colorectal cancer cells. World J Gastrointest Oncol 2014;6:289-300.

-16 Gruca A, Krawczyk Z, Szeja W, Grynkiewicz G, Rusin A: Synthetic genistein glycosides inhibiting EGFR phosphorylation enhance the effect of radiation in HCT 116 colon cancer cells. Molecules 2014;9:1855818573. 


\section{Cellular Physiology Cell Physiol Biochem 2015;35:2069-2077

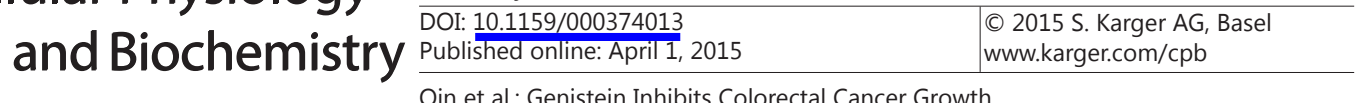

17 Majid S, Dar AA, Saini S, Chen Y, Shahryari V, Liu J, Zaman MS, Hirata H, Yamamura S, Ueno K, Tanaka Y, Dahiya R: Regulation of minichromosome maintenance gene family by microRNA-1296 and genistein in prostate cancer. Cancer Res 2010;70:2809-2818.

18 Xu L, Xiang J, Shen J, Zou X, Zhai S, Yin Y, Li P, Wang X, Sun Q: Oncogenic MicroRNA-27a is a target for genistein in ovarian cancer cells. Anticancer Agents Med Chem 2013;13:1126-1132.

19 Zaman MS, Shahryari V, Deng G, Thamminana S, Saini S, Majid S, Chang I, Hirata H, Ueno K, Yamamura S, Singh K, Tanaka Y, Tabatabai ZL, Dahiya R: Up-regulation of microRNA-21 correlates with lower kidney cancer survival. PLoS One DOI: 10.1371/journal.pone.0031060.

20 Chiyomaru T, Yamamura S, Fukuhara S, Hidaka H, Majid S, Saini S, Arora S, Deng G, Shahryari V, Chang I, Tanaka Y, Tabatabai ZL, Enokida H, Seki N, Nakagawa M, Dahiya R: Genistein up-regulates tumor suppressor microRNA-574-3p in prostate cancer. PLoS One DOI: 10.1371/journal.pone.0058929.

21 Hauptman N, Glavac D: MicroRNAs and long non-coding RNAs: prospects in diagnostics and therapy of cancer. Radiol Oncol 2013;47:311-318.

22 Tian J, Duan YX, Bei CY, Chen J: Calycosin induces apoptosis by upregulation of RASD1 in human breast cancer cells MCF-7. Horm Metab Res 2013;45:593-598.

23 Huang Z, Huang S, Wang Q Liang L, Ni S, Wang L, Sheng W, He X, Du X: MicroRNA-95 promotes cell proliferation and targets sorting Nexin 1 in human colorectal carcinoma. Cancer Res 2011;71:2582-2589.

24 Hussain A, Harish G, Prabhu SA, Mohsin J, Khan MA, Rizvi TA, Sharma C: Inhibitory effect of genistein on the invasive potential of human cervical cancer cells via modulation of matrix metalloproteinase- 9 and tissue inhibitors of matrix metalloproteinase-1 expression. Cancer Epidemiol DOI: 10.1016/j.canep.2012.07.005.

25 Zhang Y, Chen H: Genistein attenuates WNT signaling by up-regulating sFRP2 in a human colon cancer cell line. Exp Biol Med (Maywood) 2011;236:714-722.

-26 Luo Y, Wang SX, Zhou ZQ, Wang Z, Zhang YG, Zhang Y, Zhao P: Apoptotic effect of genistein on human colon cancer cells via inhibiting the nuclear factor-kappa B (NF-kB) pathway. Tumour Biol 2014;35:1148311488.

27 Chen J, Liu L, Hou R, Shao Z, Wu Y, Chen X, Zhou L: Calycosin promotes proliferation of estrogen receptor-positive cells via estrogen receptors and ERK1/2 activation in vitro and in vivo. Cancer Letters 2011;308:144-151.

28 Lang F, Böhmer C, Palmada M, Seebohm G, Strutz-Seebohm N, Vallon V: (Patho) physiological significance of the serum- and glucocorticoid-inducible kinase isoforms. Physiol Rev 2006;86:1151-1178.

29 Lang F, Perrotti N, Stournaras C: Colorectal carcinoma cells-regulation of survival and growth by SGK1. Int J Biochem Cell Biol 2010;42:1571-1575. 